Pediatria

\section{CRIANÇAS COM HIPERPLASIA CONGÊNITA DA SUPRA-RENAL TÊM VOLUME DA AMÍGDALA CEREBRAL DIMINUÍDO: CONSEQÜÊNCIAS PÓS-NATAIS}

Crianças portadoras de hiperplasia congênita da supra-renal clássica (HCSR) apresentam no período pré-natal deficiência glicocorticóide e adrenomedular, além de excesso de andrógenos com repercussão pós-natal. A masculinização pré-natal do cérebro de meninas portadoras de HCSR tem sido sugerida. Os hormônios do eixo hipotálamo-hipófiseadrenal e hormônios sexuais interagem com centros reguladores hipotalâmicos, incluindo amígdala cerebral e hipocampo.
A amígdala é importante no processo da emoção e geração do medo, enquanto que o hipocampo tem papel na memória. O hipercortisolismo crônico tem sido associado à lesão hipocampal enquanto que o glicocorticóide e o fator liberador do ACTH têm importante papel na regulação da função amigdaliana. Ressonância nuclear magnética foi realizada em 27 crianças com HCSR clássica e 47 controles. Foram quantificados os volumes do cérebro, ventrículos, lobo temporal, amígdala e hipocampo. Meninas portadoras da doença não apresentaram cérebro com características masculinas e o hipocampo foi normal. Entretanto, observou-se significativa redução do volume da amígdala cerebral em ambos os sexos'. Tal alteração, já em recém-nascidos, constitui sinal de alerta, uma vez que pode ter implicações na fisiopatologia da ansiedade e depressão na criança e adolescente.

\section{Comentário}

Tem-se procurado explicar o comportamento dos portadores de HCSR como provavelmente motivado pelos efeitos dos andrógenos sobre o cérebro, desde a vida intrauterina. Provavelmente este efeito seja secundário a alterações dos genes destes pacientes. A amigdala é área que tem dimorfismo sexual e seu volume é maior no sexo masculino. Será este dimorfismo provocado pelo excesso de esteróides sexuais das suprarenais decorrentes da HCSR ou secundário à influência gênica já determinada no feto?

Nuvarte Setian

Referência

I. Merke DP, Fields JD, Keil MF, Vaituzis AC, Chrousos GP, Giedd JN. Children with classic congenital adrenal hyperplasia have decreased amygdala volume: potential prenatal and postnatal hormonal effects. I Clin Endocrinol Metab 2003; 88:1760-5. 